\title{
Novedades en Cypella (Iridaceae) para el Paraguay: una nueva cita y la identidad de dos nombres
}

\author{
Leonardo Paz Deble ${ }^{1,2}$ Fabiano da Silva Alves ${ }^{2,3}$
}

\begin{abstract}
Resumen. Novedades en Cypella (Iridaceae) para el Paraguay: una nueva cita y la identidad de dos nombres. Cypella uliginosa es una nueva cita para la flora indígena del Paraguay. Informaciones sobre su ocurrencia en el país y las principales diferencias con las especies próximas son comentados. La identidad de los nombres Cypella amambaica y $C$. lilacea son discutidas. Además, es fornecida una clave para diferenciar las especies indígenas de Cypella en el Paraguay.

Palabras-clave: Cypella amambaica, Cypella lilacea, Cypella uliginosa, Tigridieae.
\end{abstract}

\begin{abstract}
Novelties in Cypella (Iridaceae) from Paraguay: a new record and the identity of two names. Cypella uliginosa is added for the Paraguayan Flora. Comments about its occurrence in the country and comparison about the principal differences with the close related species are supplied. The identity of the names Cypella amambaica and C. lilacea are discussed. Furthermore, a key to distinguish the native species of Cypella for Paraguay is assessed.
\end{abstract}

Key words: Cypella amambaica, Cypella lilacea, Cypella uliginosa, Tigridieae.

El estudio más reciente con las especies de Iridaceae del Paraguay fue realizado por Pierfelice Ravenna quien publicó su trabajo Flora del Paraguay-Iridaceae y en esto estudio el autor reconoció seis especies para el género Cypella (Ravenna 2003). Mismo con este importante aporte sobre esta familia botánica en el país y especialmente con el género Cypella, en que Ravenna, sin duda, es el mayor conocedor del grupo hasta los días de hoy, se hay verificado la necesidad de adicionar nuevas informaciones sobre las especies que ocurren en el país.

El primero taxón del género Cypella reconocido para el Paraguay fue C. gracilis (Klatt 1862: 545) Baker (1877: 129), que figura como indígena en el Handbook of Irideae (Baker 1892). Sin embargo, esto taxón fue excluido de la flora indígena del Paraguay (Ravenna 1981, Ravenna 2003, Ravenna 2009, Deble 2017). Más tarde, C. Hauthalii (Kuntze) Foster fue descrita para el Departamento de Paraguarí, en el sur del Paraguay, pero inicialmente ubicado bajo el nombre de Alophia Hauthalii (Kuntze 1898) y solamente más tarde transferida para Cypella (Foster 1950).
Baker (1903) en el estudio de las Plantae Hasslerianae, presentó lista y descripción de los géneros y especies de Iridaceae coleccionadas en Paraguay por el médico y naturalista suizo Emile Hassler (1864-1937), reconociendo cinco taxones para Cypella: C. coriifolia Baker (actual Trimezia spathata (Klatt) Baker), C. gracilis y C. gracilis $\mathrm{f}$. humilis Baker (ambos nombres hoy reconocidos bajo C. armosa), C. plumbea Lindley (actual Phalocallis coelestis (Lehmann) Ravenna) y $C$. Herbertii (Herbert) Herbert.

Ravenna (1981) describió ocho nuevas especies y dos nuevas subespecies para Cypella; dos de las cuales, con ocurrencia en el Paraguay: Cypella armosa Ravenna y C. curuzupensis Ravenna. Subsiguientemente, Ravenna (2000) citó la ocurrencia de $C$. laxa para la flora del referido país. Más tarde, Ravenna (2003) presentó el estudio de las Iridaceae del Paraguay, reconociendo seis especies para Cypella: C. amambaica Ravenna, $C$. armosa Ravenna, C. curuzupensis Ravenna, $C$. Hauthalii (Kuntze) Foster subsp. Hauthalii, $C$. laxa Ravenna y C. lilacea Ravenna. En una última

\footnotetext{
Aceptado en 9 de Junio de 2020 .

${ }^{1}$ Universidade Federal do Pampa - Unipampa campus Dom Pedrito, Rua 21 de abril 80, CEP 96450-000. E-mail: deble.biol@gmail.com (author for correspondence).

2 Núcleo de Pesquisas Botânicas Balduíno Rambo, Universidade Federal de Santa Maria, Av. Roraima, CEP 97105-900.

3 Curso de Ciências Biológicas, Universidade da Região da Campanha, Praça Getúlio Vargas 47, Alegrete, Rio Grande do Sul, 97542-570, Brazil. E-mail: alves.fs.bio@gmail.com
} 
contribución, validó la publicación de C. amambaica (Ravenna 2009).

Más recientemente, Deble (2017) tipificó $C$. gracilis f. humilis, nombre originalmente descrito para el Paraguay y trató la especie como un sinónimo de $C$. armosa. Además, el mismo autor comenta sobre la distribución geográfica de $C$. exilis Ravenna excluyendo esto taxón de la flora del Paraguay (Deble 2017). En otra contribución, De Baltezan et al. (2019) citaran la ocurrencia de C. Hauthalii (Kuntze) Foster subsp. opalina Ravenna (actual C. opalina (Ravenna) Deble) para el Departamento de Itapuá, en el sur del país. En un último aporte para la flora paraguaya, Deble \& Alves (2020) propusieron un nuevo tipo para $C$. curuzupensis.

Para la actualización de las especies de Cypella presentes en el Paraguay se revisó los principales herbarios del país (PY, FCQ), los herbarios CTES y SI, y fotos en alta resolución de colecciones depositados en los herbarios de Ginebra (G) y Paris (P), y además en el repositorio de tipos disponibles digitalmente en el Jstor. Fueran analizados las colectas históricas realizadas por Émile Hassler (1864-1937), que corresponden al material utilizado en la publicación de las Iridaceae de las Plantae Hasslerianae (Baker 1903). Además, tres excursiones de coleta en el Paraguay fueran realizadas, la primera en febrero de 2014, la secunda en diciembre de 2015 y la última en octubre de 2016. Con la compilación de las informaciones y datos obtenidos en las excursiones fue posible identificar algunas novedades que se dan a conocer: (1) una colecta histórica de Cypella uliginosa Deble \& F. S. Alves in Deble et al. (2015: 246) para el Paraguay; (2) la identidad del taxón nombrado bajo C. lilacea Ravenna y (3) nuevos datos sobre la posición taxonómica de C. amambaica Ravenna.

\section{Resultados y Discusión}

A continuación, se describe Cypella uliginosa, siendo adicionados informaciones sobre la ecología, habito, distribución geográfica y afinidades taxonómicas. En secuencia se comentan la identidad de los nombres Cypella amambaica y C. lilacea. Además, se fornece una clave para las especies de Cypella del Paraguay.

\section{Nuevo registro}

Cypella uliginosa Deble \& F. S. Alves, Darwiniana, nueva serie, 3(2): 237. 2015 (sect. Nais). Ty- pus: ARGENTINA. Prov. Corrientes: San Martín, La Cruz, Provincial Route 114, close to the "Bañado Guaviravi", in boggy land, flowers pale-yellow, $29^{\circ} 10^{\prime} 07,15$ ' S, 56 42 ' 51,30” W, 22.XII.2014 (fl., fr.), L. P. Deble \& F. S. Alves 15181 (Holotypus SI!; isotypus: MVFA!). (Figura 1A)

Descripción - Planta de 50-120 cm, tallo subterráneo 14-20 cm. Bulbo globoso u ovoide, 20-30 $\times 20-30 \mathrm{~mm}$, prolongado en un collar de $2 \mathrm{~cm}$, envolviendo el tallo subterráneo; catáfilos anchamente ovados, de color marrón o pajizo, agudos en el ápice. Hojas basales en la antesis 1-2, lamina plegada, linear-ensiforme, $32-68 \times 0.2-0.8$ $\mathrm{cm}$. La hoja más basal $25-54 \times 0.3-1 \mathrm{~cm}$, base envolviendo el tallo; las hojas más distales menores, oval-lanceolada, $1.5-3.5 \times 0.5-1 \mathrm{~cm}$, con la base envolviendo la base de los pedúnculos florales. Ramos floríferos $40-85 \mathrm{~cm}$ con 2-5 ramificaciones en el tercio arriba. Espatas $2-5$ por ramificación, $3.2-3.8 \times 0.2-0.4 \mathrm{~cm}$, herbáceas, verde pálidas, 2-valvadas, 1-flora, pedunculadas, pedúnculos $3.5-9.4 \mathrm{~cm}$; valva externa $1.9-2.5 \mathrm{~cm}$, valva interna $2.2-3.7 \mathrm{~cm}$, ambas agudas en el ápice, y terminando en una parte oscura, con líneas paralelas marrón-oscuro; pedicelo filiforme, 3.5-4.5 $\mathrm{cm}$. Flores amarillas o blanco-crema, $40-50 \mathrm{~mm}$ diámetro; concavidad central 26-30 mm diámetro y 6-10 $\mathrm{mm}$ de profundidad. Tépalos externos oblongos, 36-40 mm, panduriforme, cóncavo en la base por 13-16 $\mathrm{mm}$, reflejos; laminas amarillas o blanco-crema, $28-32 \times 15-18 \mathrm{~mm}$, con una línea más oscura, erectas en el tercio basal y revolutas en el ápice, truncado o redondeado, apiculado; unguículo anchamente cuneado, amarillo-claro o crema, muy translúcido $7.5-9.5 \mathrm{~mm}, 5.4-7.5 \mathrm{~mm}$ en la base, y 13-14 mm en el ápice, con escasos tricomas. Tépalos internos geniculado-recurvados, 15-20 mm longitud, la mitad proximal patente, suavemente inclinada, después curvada arriba, después con $1 / 3$ distal incurvada y fuertemente reclinada; láminas $13-15 \mathrm{~mm}$ ancho, amarilla o crema, con una depresión central oscura, en la base de una pliega, con una parte lateral más alta, con líneas paralelas oscuras y manchas irregulares; unguículo cuneado, 8-9 mm longitud, 1.5$1.8 \mathrm{~mm}$ ancho en la base y $4-5 \mathrm{~mm}$ ancho en el ápice, blanco-crema o amarillo-claro, muy translúcido, sin manchas. Filamento filiforme 3-4 mm longitud, erecto o levemente inclinados, purpuro en ambas extremidades y más claro en la porción mediana base engrosada y fusionada por $0.9-1.2$ 
$\mathrm{mm}$; anteras oblongas 7.5-8.5 × 2-2.2 mm; conectivo purpuro en ambas las extremidades y más claro en la porción mediana, $0.5-0.7 \mathrm{~mm}$ ancho, tecas oscuras, polen gris-oscuro u ocráceo. Ovario verde obovado-oblongo, $8-10 \times 2.2-3 \mathrm{~mm}$. Estilo 5-5.5 mm longitud; ramas del estilo ascendentes o erectas, 5-6 mm longitud, conadas en la mitad proximal, crestas en el ápice 3, amarillo-purpuras, las adaxiales lanceoladas, 4-5 mm, la abaxial 7-9

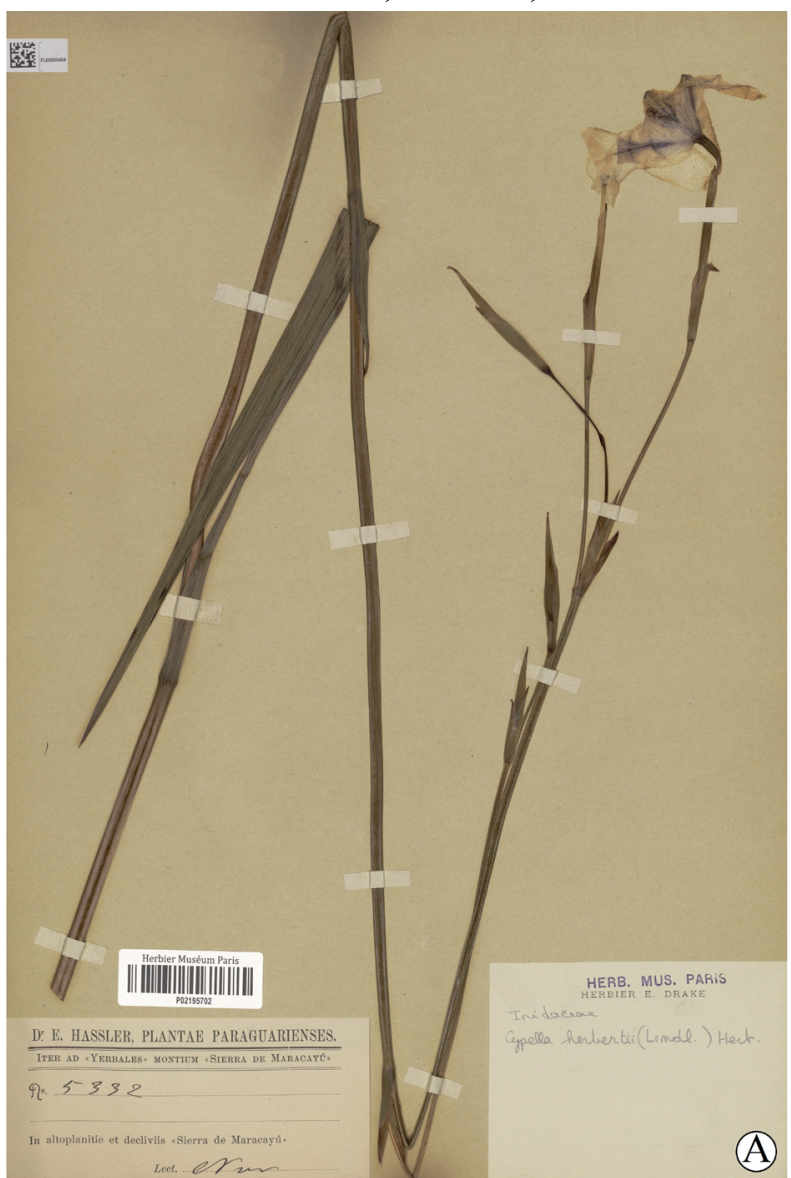

mm, conteniendo 200-340 semillas. Semillas obcónicas o triangulares, marrón-anaranjadas, 1-1.5 $\mathrm{mm}$, anguladas, epidermis lisa, con una camera de aire para fluctuación.

Etimología - Del latín "uliginosus" que significa suelos pantanosos, y se refiere al hábitat de esta especie, que crece exclusivamente en los humedales.

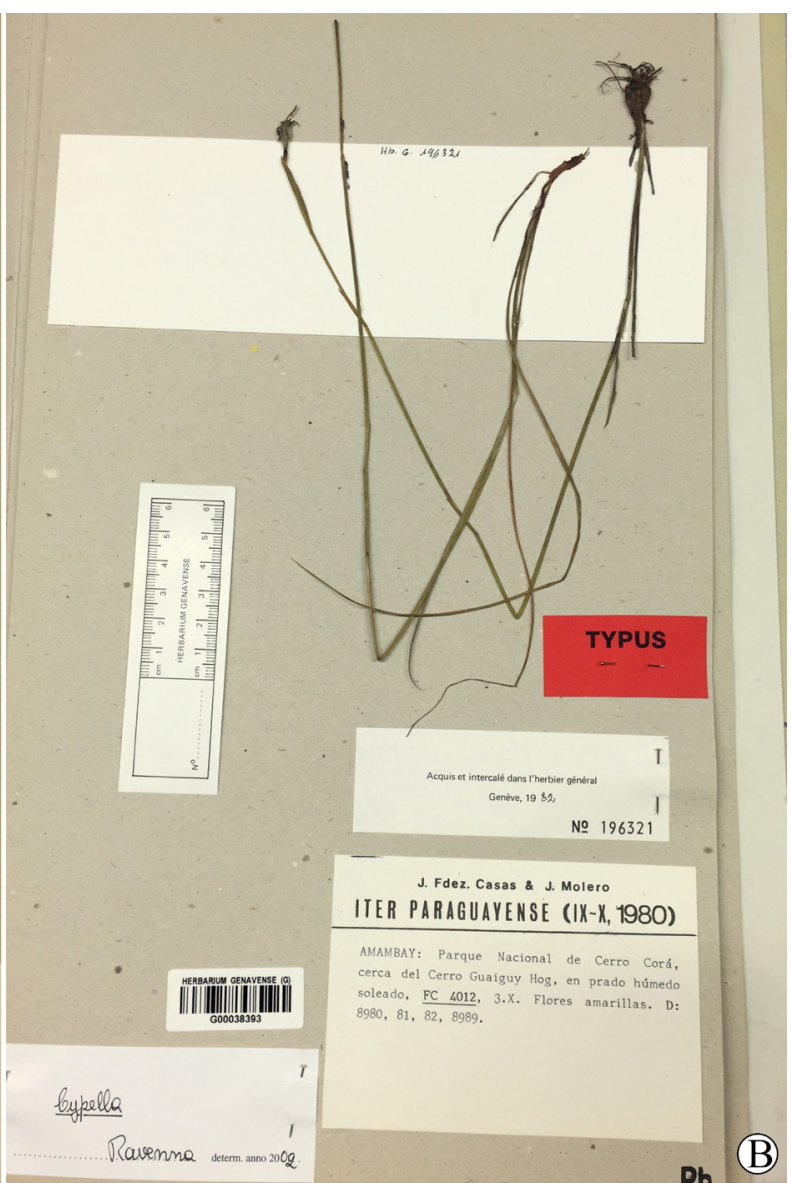

Figura 1. A.Cypella uliginosa colección histórica de E. Hassler depositado en el herbario de Paris (P0219572). B. Cypella amambaica colección tipo, depositada en el herbario de Ginebra (G00038393).

Material adicional examinado- PARAGUAY. Canindeyú: Sierra Maracayú, "in altoplanitie et decliviis", E. Hassler 5332 (P 02195702 imagen vista, P02061536 imagen vista). Concepción: Estancia Aguerito, potrero Cazal-í, hierba, flores amarillas, 24.X.1991, A. Eliceche 363 (FCQ 40527!); Flor em cultivo proveniente de Estancia San Fernando, 06.II.2014, L. P. Deble et al. 15491 (HDCF!).

Distribución y hábitat-Cypella uliginosa fue descripta basada en tres poblaciones del nordeste de la Argentina. Sin embargo, Deble et al. (2015) comentan que la especie probablemente es más común y los pocos especímenes de herbarios se dan por la dificultad de recolección en áreas pantanosas, y a la visualización de las plantas dada la vegetación de estos ambientes, además las partes vegetativas se esconden fácilmente detrás del pastizal de los pantanos, y los bulbos están bajo a la tierra a unos $20 \mathrm{~cm}$, siendo difíciles de obtener. Con la ampliación en el análisis de materiales y 
también con las nuevas coletas, fue posible identificar poblaciones de C. uliginosa en el Paraguay, donde se hay registros para los departamentos de Canindeyú y Concepción, en el sureste del país.

Comentarios - Por sus características morfológicas $C$. uliginosa puede ser confundida bajo especies de la sección Cypella. Los tépalos internos de $C$. uliginosa son geniculados y con unguículo más corto y la depresión central del perigonio poco profundo cuando comparados con los demás taxones de la sección Nais, lo que hace difícil el reconocimiento de la especie al nivel de sección, principalmente en material seco. Con base en el análisis de los herbarios fue posible verificar que Ravenna identificó C. uliginosa como Cypella armosa Ravenna, y Baker trató el material Hassler 5332 bajo Cypella Herbertii.

\section{Identidad de dos nombres}

Cypella amambaica Ravenna, Onira Botanical leaflets 12 (1): 4.2009 (sect. Cypella). Cypella amambaica Ravenna, Botanica Australis 4: 51. 2003 [sin diagnosis latina]. Cypella amambaica Ravenna, Onira Botanical Leaflets 8 (13): 43. 2003 [no válidamente publicado]. Typus: PARAGUAY. Amambay: Parque Nacional Cerro Corá, "cerca del cerro Guaiguy Hog, en prado húmedo soleado", IX-X.1980, J. Fernandez-Casas 4012 (G00038393 imagen vista!). (Figura 1B)

Descripción - Planta de 22-35 cm, tallo subterráneo $0.5-2 \mathrm{~cm}$. Bulbo globoso u ovoide, $8-15 \times$ $7-10 \mathrm{~mm}$, prolongado en un collar de $1-2 \mathrm{~cm}$; catafilos anchamente ovados, acuminados en el ápice, de color marrón claro. Hojas basales en la antesis 2-5, lámina angostamente linear 7-22 × 0.05-0.2 $\mathrm{cm}$. Hoja caulinar más basal angostamente linear, $4.5-8 \times 0.05-0.1 \mathrm{~cm}$, con hasta $2 / 3$ del total de su largo envolviendo el tallo. Ramos floríferos 20-30 $\mathrm{cm}$ de largo, sin ramificaciones. Espata única por ramo florífero, $2.1-2.9 \times 0.2-0.3 \mathrm{~cm}$, herbáceas, verdes, 2-valvadas, 1 -flora, pedunculadas, pedúnculos $2.8-4.8 \mathrm{~cm}$; valva externa $1.2-1.5 \mathrm{~cm}$, valva interna $2.1-2.9 \mathrm{~cm}$, ambas ligeramente agudas en el ápice, y terminando en una parte hialina con líneas paralelas marrón-oscuro; pedicelo filiforme, 2.5-3 cm. Flores ca. $35 \mathrm{~mm}$ diámetro, amarillo-claras; concavidad central ca. $15 \mathrm{~mm}$ diámetro. Tépalos externo oblongos, pandurados, 20-22 $\mathrm{mm}$ longitud, amarillo, cóncavo en la base por 7-8 $\mathrm{mm}$; láminas $12-14 \times 7 \mathrm{~mm}$, amarilla, suavemente patentes, ápice truncado o redondeado, apiculado; unguículo cuneado, 7-8 mm longitud, 1.5-1.9 $\mathrm{mm}$ de ancho en la base y 6-7 $\mathrm{mm}$ de ancho en el ápice, amarillo claro, translúcido, sin manchas. Tépalos internos geniculado-recurvados, 6-7 mm longitud, la mitad proximal patente, suavemente inclinada, después curvada arriba, con el 1/3 distal incurvada y fuertemente reclinada; láminas 5-6 $\mathrm{mm}$ ancho, amarilla, con una depresión central cubierto por tricomas lipídicos en la base, con una parte lateral más alta, con líneas paralelas más oscuras y manchas irregulares; unguículo cuneado, 5-5.5 mm longitud, 1.1-1.4 $\mathrm{mm}$ ancho en la base y $3.2-3.5 \mathrm{~mm}$ ancho en el ápice, amarillo-claro, translúcido. Filamentos filiformes, 2-2.5 mm, levemente inclinados, base engrosada, unido por 0.2-0.3 mm; anteras anchamente oblongas 3-3.5 $\times 1.3-1.6 \mathrm{~mm}$; conectivo $1.1-1.4 \mathrm{~mm}$ de ancho, tecas más oscuras, polen no visto. Ovario verde, obclavado, 3.5-4 $\mathrm{mm} \times 1.2-1.5 \mathrm{~mm}$. Estilo 5.4-6 $\mathrm{mm}$; ramas del estilo ascendentes, $2.5 \mathrm{~mm}$; crestas en el ápice 3, las adaxiales triangulares, 1.5-2 $\mathrm{mm}$, la abaxial triangular, ca. $0.5 \mathrm{~mm}$. Cápsula non vista.

Etimología - El epíteto amambaica se refiere al local de coleta del tipo, en el Departamento de Amambay, en el Paraguay.

Distribución y hábitat- Cypella amambaica es endémica del sureste del Paraguay, en el departamento de Amambay. La especie es conocida únicamente por el tipo. Durante expediciones botánicas realizadas en el lugar indicado en el holotipo, no se encontró $C$. amambaica, lo que sugiere la raridad de esta especie. Conforme los dados de colecta, el ambiente de ocurrencia comprende los campos húmedos asociado a vegetación de "Cerrado", al pie del cerro Guaiguy Hog.

Comentarios - La descripción presentada aquí es incompleta, teniendo en cuenta que la misma se basa en una única colecta y material seco. Las medidas de ramas del estilo y filamentos se basan en Ravenna (2003). El holotipo de C. amambaica evidencia que esta especie es morfológicamente similar a $C$. lapidosa Ravenna; sin embargo, los estambres son menores y el estilo tiene ramas más cortas con crestas triangulares. El taxón es reconocido como válido en Las Iridaceae del Paraguay (Ravenna 2003) y en Survey on Cypella and its allies (Ravenna 2009). Sin embargo, es listada 
como dudosa en Flora del Conosur (2020). Por sus caracteres morfológicos $C$. amambaica debe ser reconocida como un nombre válido perteneciente a la sección Cypella.
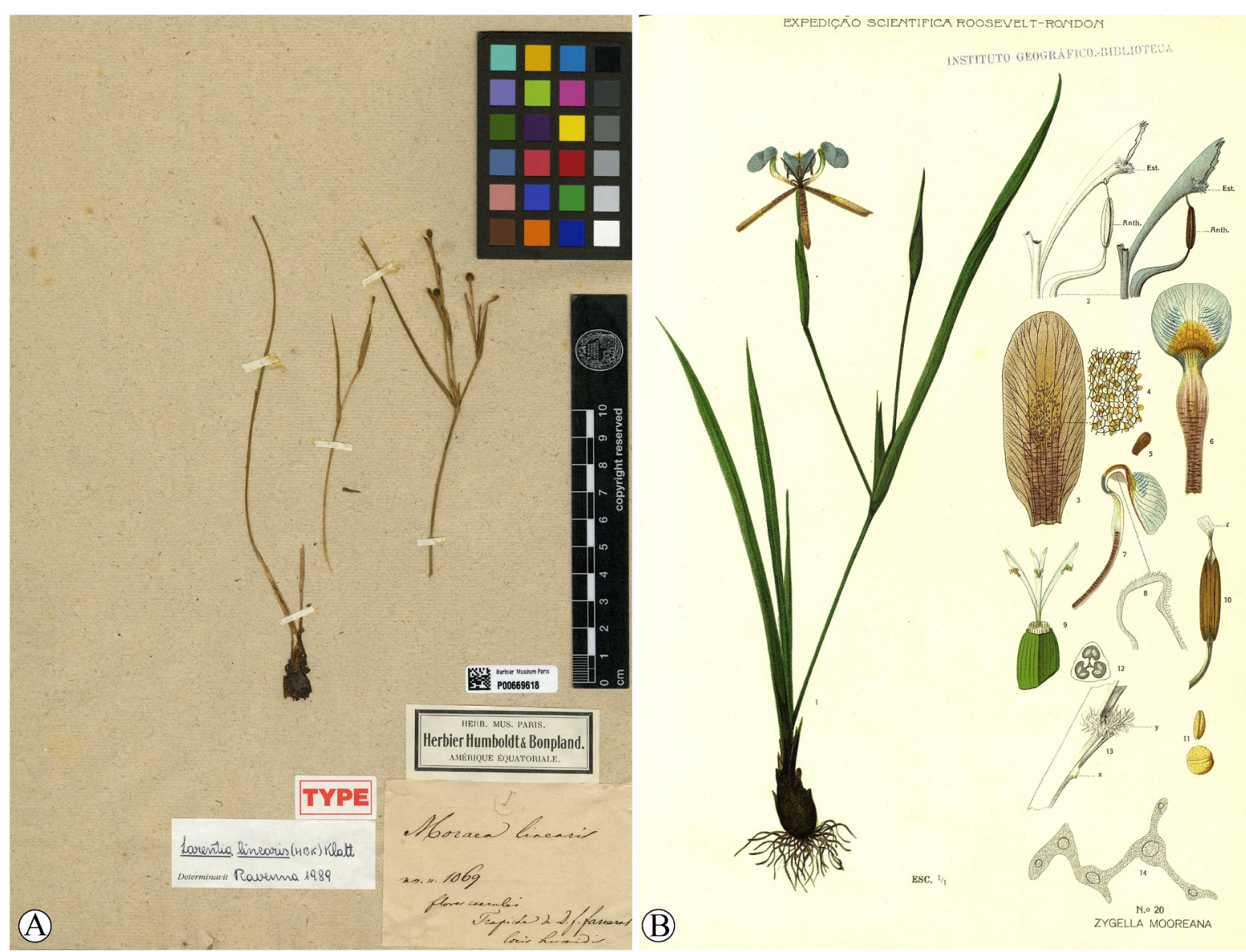

Figura 2. A. Larentia linearis colección tipo de Moraea linearis, depositada en el herbario de Paris (P00669618). B. Larentia linearis, epitipo de Zygella moreana, según Goldblatt \& Celis (2010).

Larentia linearis (Kunth) Klatt, Abh. Naturf. Ges. Halle 15: 362. $1882 \equiv$ Moraea linearis Kunth in F.W.H. von Humboldt, A.J.A. Bonpland \& C.S. Kunth, Nov. Gen. Sp. 1: 321. 1816. 三 Marica linearis (Kunth) Ker Gawl., Irid. Gen.: 24. 1827. $\equiv$ Alophia linearis (Kunth) Klatt, Linnaea 31: 558. 1862. $\equiv$ Sphenostigma lineare (Kunth) Benth. \& Hook.f., Gen. P1. 3: 695. 1883. 三 Cypella linearis (Kunth) Baker, Handb. Irid.: 65. 1892. Typus: VENEZUELA, "Crescit in humidis calidisque Guayanae prope El Trapiche de Farreras. Floret Junio" A. J. A. Bonpland \& F. W. H. A. von Humboldt 1069 (Holotypus P00669618 imagen visto!). (Figuras 2A, B y 3A, B)

= Zygella graminea S.Moore, Trans. Linn. Soc. London, Bot. 4: 494. 1895. Typus: BRASIL. Mato Grosso: "Viget Santa Cruz, ubi reperi mens." XII-1891, S. L. Moore 733 (Holotypus NY00319559 imagen visto!).
= Zygella mooreana Hoehne, Relat. Commiss. Linhas Telegr. Estratég. Matto Grosso Amazonas 1: 19. 1910. Typus: BRASIL. Mato Grosso: Porto Esperidiao, Hoehne s.n. Original material desconocido. Epitypus (designado por Goldblatt \& Celis 2010 413): Figura 58, p. 20 en Relat. Commiss. Linhas Telegr. Estratég. Matto Grosso Amazonas, 1910.

= Cypella lilacea Ravenna, Onira Botanical leaflets 9 (1): 3 . 2003 [no validamente publicado]. Botanica Australis 4: 51. 2003 [sin diagnosis latina]. Original Material: PARAGUAY. Concepción, Estancia San Fernando, 11.XII.1991, I. Basualdo 3903 (FCQ28158!).

Descripción - Planta de 10-40 cm, tallo subterráneo $2-8 \mathrm{~cm}$. Bulbo globoso u ovoide, 10-20 × $10-18 \mathrm{~mm}$, prolongado en un collar corto, envolviendo el tallo subterráneo; catáfilos anchamente ovados, de color marrón oscura, agudos en el ápice. Hojas basales en la antesis ausente o hasta 4, lamina plegada, linear-ensiforme, $8-18 \times 0.2-0.8$ 
$\mathrm{cm}$. La hoja más basal $8-22 \times 0.2-0.6 \mathrm{~cm}$, base envolviendo la base de los pedúnculos florales. Ramos floríferos $10-25 \mathrm{~cm}$ con 1-2 ramificaciones en el tercio arriba. Espatas 2-5 por ramificación, $1.9-3.5 \times 0.2-0.3 \mathrm{~cm}$, herbáceas, verde pálidas, 2-valvadas, 1-flora, pedunculadas, pedúnculos $1.5-8 \mathrm{~cm}$; valva casi iguales, naviculares, la externa $1.6-3.2 \mathrm{~cm}$, valva interna $1.9-3.4 \mathrm{~cm}$, ambas agudas en el ápice, y terminando en una parte más oscura; pedicelo filiforme, $2.5-3.8 \mathrm{~cm}$. Flores violeta-azuladas, 25-40 mm diámetro. Tépalos externos espatulados, 16-25 $\mathrm{mm}$, patentes en inclinación de $\pm 45^{\circ}$; laminas violeta-azuladas en la mitad distal, después amarillo-claro o crema con líneas marrón-rojizas o púrpuras; lámina violeta-azulada, ovada o casi circular, 9-14 × 7-11 $\mathrm{mm}$, truncado o redondeado en el ápice y cuneada o rotunda en la base; unguículo oblongo, amarillo-claro o crema, con líneas marrón-rojizas o púrpuras, $7-15 \mathrm{~mm}, 2.5-3.5 \mathrm{~mm}$ en la base, y $2.5-4 \mathrm{~mm}$ en el ápice, con escasos tricomas. Tépalos internos arqueado-recurvados, $15-20 \mathrm{~mm}$ longitud, la mitad proximal arqueada, después curvada arriba, y reclinado uncinadas en la parte más distal; láminas 8-10 $\mathrm{mm}$ ancho, violeta-azulada y con líneas violeta-oscura, con una depresión central más clara y con una mácula amarilla o amarillo-oro central, en la base de una pliega, con una parte lateral más alta; unguículo angostamente cuneado, 6-12 mm longitud, 1.5-2 $\mathrm{mm}$ ancho en la base y $3-3.5 \mathrm{~mm}$ ancho en el ápice, blanco-crema o amarillo-claro, con manchas marrón-rojizas o púrpuras. Filamento filiforme 4-6 mm longitud, patente-arqueados, blanco crema en la parte distal, base más engrosa- da y rojiza; anteras oblongas 3-4.5 × 2-2.2 mm; conectivo amarillo, muy angosto y prolongado en un apéndice apical, tecas oscuras, polen amarillo-oro. Ovario verde obovado u oblongo, 3-8 $\times$ 1.5-4 mm. Estilo azul-celeste o violeta-azulado, translucido, 10-16 $\mathrm{mm}$ longitud; base $2-4 \mathrm{~mm}$, ramas del estilo ascendentes, $8-11 \mathrm{~mm}$ longitud, totalmente libres, crestas en el ápice 2, ambas adaxiales, falcadas, $1-3 \mathrm{~mm}$, línea estigmática en la cara abaxial, en la base de las crestas. Capsula ovado-oblonga, 5-10 × 3-5 mm. Semillas obcónicas pardo-oscuras o marrón-rojizas, ca. $1 \mathrm{~mm}$, anguladas, epidermis reticulada.

Distribución y hábitat-Larentia linearis es ampliamente distribuida en la parte tropical de la América del Sur, donde ocurre en Norte de la Argentina, Bolivia, Colombia, Venezuela, Paraguay y centro-oeste del Brasil.

Comentarios - Durante la revisión del herbario FCQ fue localizado la colección I. Basualdo 3903, el tipo de Cypella lilacea según Ravenna (2003). Sin embargo, este material presenta una única flor, que está incompleta. Mismo así, fue posible realizar la ilustración aquí presentada y sin duda, el material tiene los siguientes caracteres morfológicos que relacionan a Larentia: las anteras con apéndice apical y los ramos del estilo con dos crestas acudas y sin cresta abaxial. Además, las medidas de flores, espatas y el habito general sin duda coinciden perfectamente con Larentia linearis, así consideramos $C$. lilacea como un sinónimo de L. linearis.

\section{Clave para las especies de Cypella ocurrentes en el Paraguay}

1. Espatas 2-flora. Flores blancas o lilas. Tépalos internos con unguículo linear; láminas hastadas, erecto-ascendentes y después recurvas y uncinadas en el ápice

- Espatas 1-flora. Flores amarillas o doradas. Tépalos internos con unguículo cuneado; laminas no hastadas, recurvado-reflejas o ascendente-reflejas

2. Flores lilas. Tépalas externos ascendentes en la mitad proximal; tépalos internos más largos que la depresión central. Estilo 18-23 mm longitud Cypella Hauthalii

- Flores blanco o blanco-azuladas. Tépalos externos erectos en la mitad proximal; tépalos internos más cortos que la depresión central. Estilo 13-17 mm longitud .... Cypella opalina

3. Tépalos internos con unguículo más corto que la lámina, tricomas lipídicos dispuestos en una banda central cerca de la base de la depresión central (sect. Cypella)

- Tépalos internos con unguículo más largo que la lámina, tricomas lipídicos dispuestos en una banda central cerca de la parte media de la depresión central (sect. Nais) 
Deble, L.P. \& F.S. Alves, Cypella en Paraguay.

4. Plantas frecuentes en toda porción oriental del Paraguay. Espatas de 4-5.6 × 0.3-0.4 cm Ramas del estilo ca. 6-7 mm. Anteras $7-8 \mathrm{~mm}$ Cypella armosa

- Plantas del departamento de Amambay. Espatas de 2.1-2.9 × 0.2-0.3 cm. Ramas del estilo ca. $2.5 \mathrm{~mm}$. Anteras 3-3.5 mm .....

5. Plantas muy gráciles, con hojas basales de 1-2 mm de ancho y 1-2 espatas por ramificación

Cypella amambaica

- Plantas más robustas, con hojas basales de 2-8 $\mathrm{mm}$ de ancho y 2-5 espatas por ramificación ...

Cypella uliginosa

6. Tépalos internos 16-20 × 8-11 mm, unguículo angostamente cuneado. Filamentos y anteras de igual largo

Cypella curuzupensis

- Tépalos internos 16-20 × 11-16 mm, unguículo cuneado. Anteras cerca de dos veces más larga que los filamentos

Cypella laxa
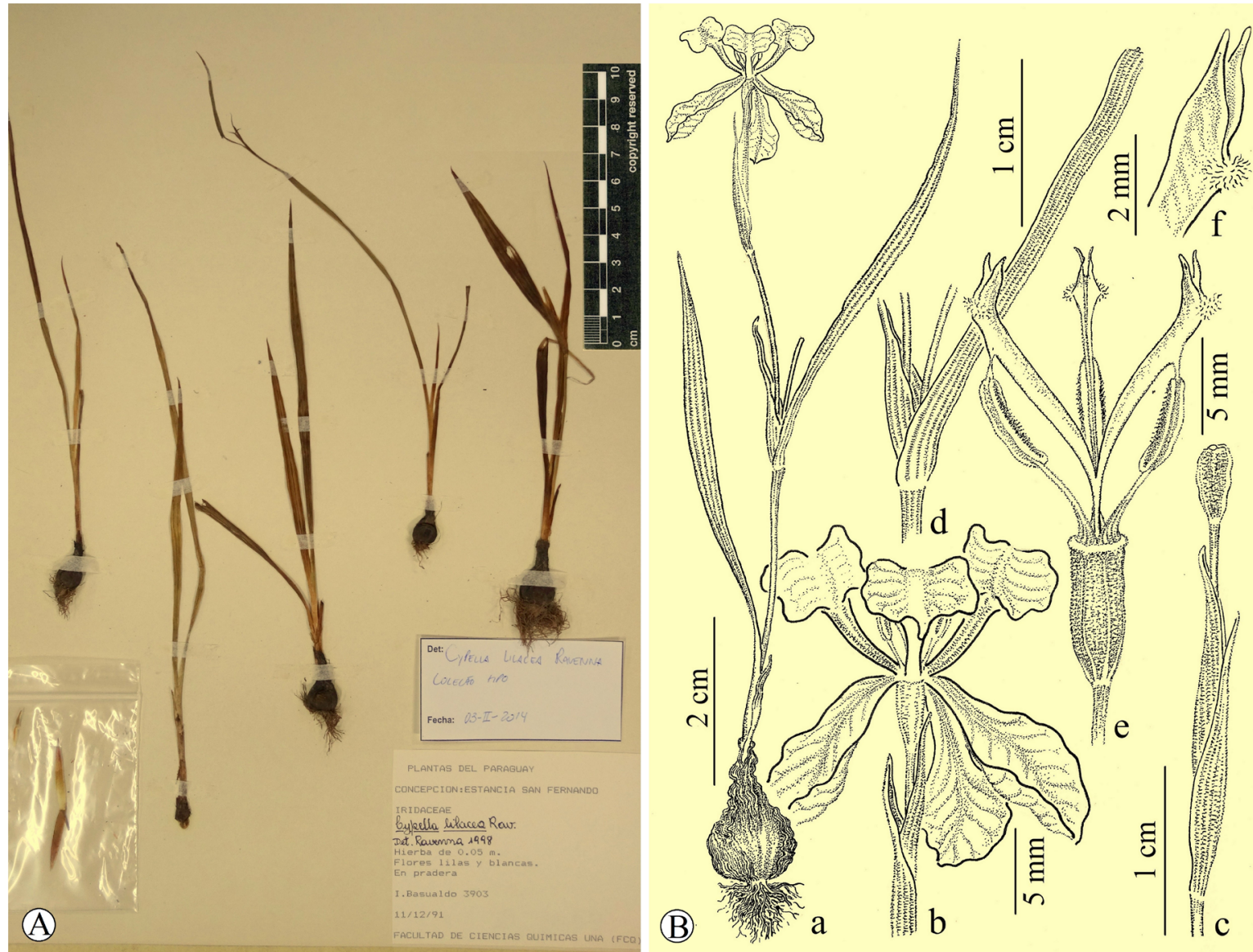

Figura 3. A. Larentia lineris, original colección de Cypella lilacea (FCQ 28158). B. Ilustración de la colección I. Basualdo 3903: a. habito, b. flor, c. espata con fruto inmaturo, d. parte basal de la hoja tectriz, e. flor con lo perigonio sacado, f. detalle del ápice de las ramas del estilo. La flor y los detalles floráis se basan en rehidratación.

\section{Agradecimientos}

Agradecemos a los curadores y funcionarios de los herbarios mencionados, también a Lídia Perez Molas y Tomás Ríos por su suporte durante las excursiones al Paraguay y Lorenzo Ramella, Editor Flora del Paraguay por la disponibilidad de imágenes del tipo de Cypella amambaica.

\section{Referencias}

Baker, J.G. 1877. Systema Iridacearum. Journal of Linnean Society, Botany 16: 61-180. http://dx.doi.org/10.1111/j.1095-8339.1877.tb00172.x

Baker, J.G. 1892. Handbook of the Irideae. London: George Bells \& Sons. 248 pp. http://dx.doi.org/10.5962/bhl.title.15431

Baker, J.G. 1903. Iridaceae Plantae Hassleriana. Bulletin de l'Herbier Boissier ser. 2, vol. 3: 1102-1106. 
De Baltezán, M.M., A. Santos \& L.P. Deble. 2019. Cypella hauthalii (Kuntze) Foster subsp. opalina Ravenna (Iridaceae: Tigridieae) nueva cita para el Paraguay. Balduinia 65: 35-39.

Deble, L.P., F. da S. Alves \& A.S. de Oliveira. 2015. Three new species of the genus Cypella (Iridaceae, Tigridieae). Darwiniana, nueva série 3, n. 2: 235-253. http://dx.doi.org 10.14522/darwiniana.2015.31.666

Deble, L.P. La identificación de Cypella exilis Ravenna (Iridaceae). Balduinia 56: 27-34.

Deble, L.P., F. da S. Alves. 2020. Cypella (Iridaceae): What do we know about the diversity of the genus? Balduinia 66. (en prensa)

Flora del Conosur. 2020. Catálogo de plantas vasculares. Available from: http://www2.darwin.edu.ar/Proyectos/ FloraArgentina/FA. 2009 (consulta en 27 de enero de 2020).

Foster, R.C. 1950. Studies in the Iridaceae VI, Miscelaneous novelties and transfers. Contributions from the Gray Herbarium of Harvard University 171: 22-28.
Klatt, F.W. 1862. Specimen e familia Iridacearum. Linnaea 31: 533-570.

Kuntze, O. 1898. Iridaceae. Revisio Generum Plantarum 3: 304-309. http://dx.doi.org/10.5962/bhl.title.327

Goldblatt, P. \& M. Celis. 2010. Zygella S. Moore, a synonym of Larentia Klatt (Iridaceae). Novon 20, n. 4: 412-413.

Ravenna, P.F. 1981. Eight new species and two new subspecies of Cypella (Iridaceae). Wrightia 7 (1): 13-21.

Ravenna, P.F. 2000. Cypella laxa (Iridaceae) reported in the flora of Paraguay. Onira Botanical Leaflets 4: 1-2.

Ravenna, P.F. 2003. Flora de Paraguay. Iridaceae. Botanica Australis 4: 1-60. 2003.

Ravenna, P.F. 2009. A survey in the genus Cypella and its allies (Iridaceae). Onira Botanical Leaflets 12, n. 1: 1-11. 